\title{
Kojic Acid Production from Agro-Industrial By-Products Using Fungi
}

\author{
Ismael A. El-Kady, ${ }^{1}$ Abdel Naser A. Zohri, ${ }^{1}$ and Shimaa R. Hamed ${ }^{2}$ \\ ${ }^{1}$ Botany Department, Faculty of Science, Assiut University, Assiut 71515, Egypt \\ ${ }^{2}$ Microbial Biotechnology Department, National Research Center, Dokki 12622, Egypt \\ Correspondence should be addressed to Shimaa R. Hamed; shemo22003@yahoo.com
}

Received 4 November 2013; Revised 4 February 2014; Accepted 4 February 2014; Published 23 March 2014

Academic Editor: Manuel Canovas

Copyright (c) 2014 Ismael A. El-Kady et al. This is an open access article distributed under the Creative Commons Attribution License, which permits unrestricted use, distribution, and reproduction in any medium, provided the original work is properly cited.

\begin{abstract}
A total of 278 different isolates of filamentous fungi were screened using synthetic medium for respective ability to produce kojic acid. Nineteen, six, and five isolates proved to be low, moderate, and high kojic acid producers, respectively. Levels of kojic acid produced were generally increased when shaking cultivation was used rather than those obtained using static cultivation. A trial for the utilization of 15 agro-industrial wastes or by-products for kojic acid production by the five selected higher kojic acid producer isolates was made. The best by-product medium recorded was molasses for kojic acid. A. flavus numbers 7 and 24 were able to grow and produce kojic acid on only 12 out of 15 wastes or by-products media. The best medium used for kojic acid production by $A$. flavus number 7 was rice fragments followed by molasses, while the best medium used for kojic acid production by A. flavus number 24 was the molasses followed by orange, pea, and rice fragments. An attempt for production of kojic acid using a $1.5 \mathrm{~L}$ laboratory fermentor has been made. Aspergillus flavus number 7 was used and grown on molasses medium; maximum level (53.5 g/L) of kojic acid was obtained after eight days of incubation.
\end{abstract}

\section{Introduction}

Kojic acid is a metabolic product of several species of the economically valuable genus Aspergillus. This mold is used in the production of a number of foods, including miso (soybean paste), shoyu (soy sauce), and sake, which are produced throughout the world. This mold is also used in the production of other fermented products including amazake (a sweet beverage), shochu (a distilled liquor), and mirin (a sweet, alcoholic seasoning), which are consumed primarily among the Japanese. Because kojic acid is produced during the fermentation of these historically used dietary staples, it has a long history of consumption. Health foods containing kojic acid are widely sold in Japan [1]. Kojic acid is permitted for addition to foods in Japan [2]. Kojic acid has been added to food as an antioxidant [3], as a preservative to prevent formation of warmed-over flavor in beef [4], as a processing aid to inhibit the formation of nitrosopyrrolidine in fried bacon [5], and to produce reddening in unripe strawberries [6]. It has also been used as a starting material for synthesis of the flavor enhancer's maltol [7]. Yellow product formation takes place when both kojic acid and $o$-quinones are present. Kojic acid and some of its derivatives are used in cosmetic preparations to achieve a skin-lightening effect by inhibiting melanin formation and through a UV light protective action. Kojic acid also enhances shelf life of the product through its preservative actions against both chemical and microbial degradation $[8,9]$. In addition, kojic acid has been used as an antibiotic, pesticide, and analytical chemical (in the determination of thorium and rare earths) as recorded by many investigator [10-12]. Utilization of industrial waste or by-products for the fungal production of useful products has been recommended by many investigations such as glycerol production by filamentous fungi using cheese whey [1315], lipid, and sterol and ergosterol production by fungi using sugar cane molasses or cheese whey [16-18] and sidechain degradation and some biological transformation of progesterone by fungi using sugar cane molasses [19] and cyclosporin A production by fungi grown on agro-industrial wastes of some fruits, vegetables, and pickles as well as 
molasses and corn steeps [20-22]. The objective of this study was to study the following: the potentialities of kojic acid and production by 278 different fungal isolates; comparison between static and shaking cultivation methods for the production; optimization of both nutritional and environmental factors affecting the acid production; and utilization of 15 kinds of agro-industrial wastes or by-products by the high kojic acid producers for acid formation as well as production of this product on semi-industrial scale using a laboratory fermentor.

\section{Materials and Methods}

2.1. Tested Isolates. Two hundred and seventy-nine isolates of seventy-three species and one species variety represented sixteen genera of filamentous fungi collected during this study were examined for kojic acid production. These different isolates were obtained from the Botany Department, Faculty of science, Assiut University, Egypt, and AUMC (Assiut University Mycological Center), Assiut University.

2.2. Medium and Fermentation. The optimized medium for kojic acid production by $A$. flavus Link as proposed by Madiha et al. [23] was used in all experiments for inoculum preparation and also for kojic acid fermentation. The experimental cultures were grown in $250 \mathrm{~mL}$ Erlenmeyer flasks, each containing $50 \mathrm{~mL}$ of the synthetic medium. The flasks were sterilized at $121^{\circ} \mathrm{C}$ for $20 \mathrm{~min}$ and inoculated after cooling with $2 \mathrm{~mL}$ of 7 - to 10 -day-old cultures. The inoculum spore suspensions were prepared by adding sterile distilled water to the slant culture, followed by gentle agitation. The final concentration of spore's suspension was about $5 \times 10^{6}$ spores per $\mathrm{mL}$. The cultures were incubated at $28 \pm 2^{\circ} \mathrm{C}$ as stationary cultivation for 15 days.

\subsection{Agro-Industrial Wastes and By-Products Used as Culture Media}

(1) Fruits, Vegetables, and Pickle Wastes and Agriculture ByProducts. Each individual fungal isolate of the highly kojic acid producers (five isolates) was cultivated on semisynthetic culture media. Each medium contained $100 \mathrm{~g}$ of agroindustrial waste product, individually, of each of orange, peach, apple, and apricot as fruit wastes; pea, mixed vegetable, and kidney beans as vegetables wastes; carrot and turnip as pickle wastes as well as wheat bran, rice fragments, and rice husk as agriculture by-products added to one liter of distilled water and supplemented with $5 \mathrm{~g} / \mathrm{L}$ of yeast extract. All industrial wastes were collected from different juices, vegetables canning, and pickles factories located at the industrial areas of different governorates in Egypt, while the three agricultural by-products were collected from different farms of different governorates in Egypt.

(2) Corn Steep Liquor. Corn steeps liquor was prepared by using sweet corn maize. $100 \mathrm{~g}$ from the substrate was put in $2000 \mathrm{~mL}$ Erlenmeyer flasks and completed to $2000 \mathrm{~mL}$ by distilled water and cooked on a very quiet flame for $12 \mathrm{~h}$; after that, these were filtered through a muslin cloth and used. Each individual fungal isolate of the highly kojic acid producers was cultivated on a medium consisting of $100 \mathrm{~mL}$ of corn steep liquor added to $900 \mathrm{~mL}$ of distilled water to complete one liter medium.

(3) Cheese Whey. Salted cheese whey is a by-product formed from milk during the production of cheese (both soft and hard cheese). Whey used during this work was produced from milk composed of 1:1 cow's and buffalo's milk which were used for production of white soft (Domiati type) cheese. Whey sample was kindly provided by Dairy Department, Faculty of Agricultural, Assiut University. Samples of whey $(8 \% \mathrm{NaCl})$ were centrifuged $(5000 \mathrm{rpm}, 10 \mathrm{~min})$, the sediment was discarded, and samples of supernatant were used as it is.

(4) Black-Strap Molasses. Black-strap molasses supplemented from El-Hawamdya sugar cane factory were tested as natural medium for cultivation of the experimental organisms. The molasses sample was centrifuged $(5000 \mathrm{rpm}, 10 \mathrm{~min})$, the muddy sediment was discarded, and samples of supernatant were tested. Each individual fungal isolate of the highly kojic acid producers was cultivated on liquid semisynthetic medium of the following composition: supernatant molasses sample, $100 \mathrm{~mL}$; yeast extract, $5.0 \mathrm{~g}$; and completed to one liter distilled water. The $\mathrm{pH}$ of the different media was adjusted at 3.0 before sterilization. The cultures were incubated at $28 \pm 2^{\circ} \mathrm{C}$ on rotary shaker $(220 \mathrm{rpm})$ for 10 days.

2.4. Quantitative Determination of Kojic Acid. Kojic acid was determined using a spectrophotometric method with 2,6 dichlorophenolindophenol (DCIP) as recorded by Tanigaki et al. [7].

2.5. Production of Kojic Acid on Semi-Industrial Scale. A 1.5-liter B. Braun stirred tank (Biostat. A) fermentor (from B. Braun Biotech. International, Sortorius group, $\mathrm{GmbH}$, Schwarzenberger, Germany) with one liter working volume was used in this study. The fermentor was equipped with $\mathrm{pH}$, temperature, agitation, dissolved oxygen tension (DOT), and foam controllers. Seed cultures were carried out in $250 \mathrm{~mL}$ flask containing $50 \mathrm{~mL}$ of medium, held on a rotary shaker at $150 \mathrm{rpm}$, at $28^{\circ} \mathrm{C}$ for $48 \mathrm{~h}$. Seed culture flask $(50 \mathrm{~mL})$ from fungal isolates (Aspergillus flavus number 7), which proved to be the higher kojic acid producer, was used to inoculate the fermentor at $30^{\circ} \mathrm{C}$. Fermentation lasted around 14 days. The culture medium was modified synthetic medium consisting of $(\mathrm{g} / \mathrm{L})$ : glucose, 100; yeast extract, 5.0; $\mathrm{KH}_{2} \mathrm{PO}_{4}, 1.5$; and $\mathrm{MgSO}_{4} \cdot 7 \mathrm{H}_{2} \mathrm{O}, 0.5$. The $\mathrm{pH}$ was adjusted to 3.0 , temperature at $30^{\circ} \mathrm{C}$, and agitation at $400 \mathrm{rpm}$, while the DOT in the culture broth was controlled via a sequential cascade control as air flow rate. The maximum and minimum set points of permitted airflow rates were $1.2 \mathrm{~L} / \mathrm{min}$ and $0.1 \mathrm{~L} / \mathrm{min}$, respectively. The DOT during fermentation was controlled at medium $(\sim 50 \%)$ of saturation. 
TABle 1: Production of kojic acid by different isolates belonging to various species and varieties of Aspergillus and their teleomorph.

\begin{tabular}{|c|c|c|c|c|c|c|}
\hline \multirow{2}{*}{ Organisms } & \multirow{2}{*}{ Code number } & \multirow{2}{*}{ Total isolates tested } & \multirow{2}{*}{-ve isolates } & \multicolumn{3}{|c|}{ +ve isolates } \\
\hline & & & & Low $^{*}$ & Moderate $e^{* *}$ & High $^{* * *}$ \\
\hline \multicolumn{7}{|l|}{ Subgenus: circumdati } \\
\hline \multicolumn{7}{|l|}{ Section: candidi } \\
\hline A. Candidus Link & 2 & 1 & 1 & - & - & - \\
\hline \multicolumn{7}{|l|}{ Section: circumdati } \\
\hline A. melleus Yukowa & $78-80$ & 3 & 3 & - & - & - \\
\hline A. Ochraceus Wilhelm & $100-113$ & 14 & 14 & - & - & - \\
\hline A. sclerotiorum Hoper & 121 & 1 & - & 1 & - & - \\
\hline A. Sulphureus (Fres.) Thom and Church & 122,123 & 2 & 2 & - & - & - \\
\hline \multicolumn{7}{|l|}{ Section: Flavi } \\
\hline A. flavus Link & $4-32$ & 29 & 23 & 3 & - & 3 \\
\hline A. flavus var. columnaris Raper and Fennell & $36-63$ & 28 & 25 & 1 & 1 & 2 \\
\hline A. Oryzae (Ahlburg) Cohn & 115,116 & 2 & 2 & - & - & - \\
\hline A. Parasiticus Spear & 117,118 & 2 & 2 & - & - & - \\
\hline A. tamarii Kita & 129,130 & 2 & - & - & 2 & - \\
\hline \multicolumn{7}{|l|}{ Section: Nigri } \\
\hline A. aculeatus Lizuka & 1 & 1 & 1 & - & - & - \\
\hline A. niger van Tieghem & $81-99$ & 19 & 19 & - & - & - \\
\hline A. phoenicis (Cda.) Thom & 119,120 & 2 & - & 2 & - & - \\
\hline \multicolumn{7}{|l|}{ Section: wentii } \\
\hline A. wentii Wehmer & $144-146$ & 3 & 2 & 1 & - & - \\
\hline \multicolumn{7}{|l|}{ Subgenus: fumigati } \\
\hline \multicolumn{7}{|l|}{ Section: Fumigati } \\
\hline A. fumigatus Fresenius & $64-75$ & 12 & 12 & - & - & - \\
\hline \multicolumn{7}{|l|}{ Subgenus: Nidulantes } \\
\hline \multicolumn{7}{|l|}{ Section: Flavipedes } \\
\hline A. flavipes (Bain. and Sart) Thom and Church & 3 & 1 & 1 & - & - & - \\
\hline \multicolumn{7}{|l|}{ Section: Terii } \\
\hline A. terreus Thom & $131-139$ & 9 & 8 & - & 1 & - \\
\hline \multicolumn{7}{|l|}{ Section: Versicolores } \\
\hline A. Janus Raper and Thom & 77 & 1 & 1 & - & - & - \\
\hline A. sydowii (Bain. and Sart) Thom and Church & $124-127$ & 4 & 4 & - & - & - \\
\hline A. versicolor (Vuill.) Tiraboschi & 143 & 1 & - & - & 1 & - \\
\hline Emericella nidulans (Eidam) Vuillemin & $147-150$ & 4 & 3 & 1 & - & - \\
\hline Eurotium amstelodami Mangin & 151 & 1 & - & 1 & - & 5 \\
\hline Total & - & 142 & 122 & 10 & 5 & 5 \\
\hline
\end{tabular}

${ }^{*}$ Less than $5 \mathrm{~g} / \mathrm{L}$ medium kojic acid.

${ }^{* *} 5-15 \mathrm{~g} / \mathrm{L}$ medium kojic acid.

${ }^{* * *}$ More than $5 \mathrm{~g} / \mathrm{L}$ medium kojic acid.

\section{Results and Discussion}

Screening the abilities of 278 different fungal isolates belonging to 16 genera and 71 species in addition to one species variety for kojic acid production was an aim in this study. Aspergillus was represented by 135 isolates of 18 species and one variety belonging to nine sections (Table 1). High concentrations (more than $15 \mathrm{~g} / \mathrm{L}$ medium) of kojic acid were produced by only three isolates of A. flavus (numbers 7 , 23, and 24) and two isolates of A. flavus var. columnaris (numbers 36 and 41). Moderate levels (5 to $15 \mathrm{~g} / \mathrm{L}$ medium) were obtained by five Aspergillus isolates one of each of
A. flavus var. columnaris, number 39; A. terreus, number 131, and $A$. versicolor, number 143 in addition to two isolates of A. tamarii (numbers 129 and 130), while low concentrations (less than $5 \mathrm{~g} / \mathrm{L}$ medium) were obtained by eight Aspergillus isolates as follows: three isolates of A. flavus (numbers 4, 9, and 32), two of $A$. phoenicis (numbers 119 and 120) in addition to one isolate of each of $A$. sclerotiorum (number 121), A. flavus var. columnaris (number 43), and $A$. wentii (number 145). It is worth mentioning that 12 out of the 18 Aspergillus isolates, which recorded as kojic acid producers, belonging to two species (A. flavus and A. tamarii) and one species variety (A. flavus var. columnaris) of section flavi 
TABLE 2: Production of kojic acid by different isolates belonging to various species of Penicillium.

\begin{tabular}{|c|c|c|c|c|c|c|}
\hline \multirow{2}{*}{ Organisms } & \multirow{2}{*}{ Code number } & \multirow{2}{*}{ Total isolates tested } & \multirow{2}{*}{-ve isolates } & \multicolumn{3}{|c|}{ +ve isolates } \\
\hline & & & & Low $^{*}$ & Moderate $e^{* *}$ & $\operatorname{High}^{* * *}$ \\
\hline \multicolumn{7}{|l|}{ Subgenus: aspergilloides } \\
\hline P. Capsulatum Raper and Fennell & $159-163$ & 5 & 5 & - & - & - \\
\hline P. lividum Westling & $218-220$ & 3 & 3 & - & - & - \\
\hline P. spinulosum Thom & 230,231 & 2 & 1 & 1 & - & - \\
\hline \multicolumn{7}{|l|}{ Subgenus: biverticillium } \\
\hline P. funiculosum Thom & 213 & 1 & 1 & - & - & - \\
\hline P. purpurogenum Stoll & 227,228 & 2 & 2 & - & - & - \\
\hline P. rugulosum Thom & 229 & 1 & 1 & - & - & - \\
\hline \multicolumn{7}{|l|}{ Subgenus: furactum } \\
\hline P. citrinum Thom & $187-201$ & 15 & 15 & - & - & - \\
\hline P. corylophilum Dierckx & 202,203 & 2 & 2 & - & - & - \\
\hline P. herquei Bain. and Sart. & 215 & 1 & 1 & - & - & - \\
\hline P. janthinellum Biourge & 216,217 & 2 & 1 & 1 & - & - \\
\hline \multicolumn{7}{|l|}{ Subgenus: penicillium } \\
\hline P. albidum Sopp & 152 & 1 & 1 & - & - & - \\
\hline P. atramentosum Thom & 153 & 1 & 1 & - & - & - \\
\hline P. aurantiogriseum Dierckx & 154 & 1 & - & 1 & - & - \\
\hline P. camemberti Thom & 156,157 & 2 & 2 & - & - & - \\
\hline P. chrysogenum Thom & $164-185$ & 22 & 22 & - & - & - \\
\hline P. cyaneofulvum Biourge & 205 & 1 & 1 & - & - & - \\
\hline P. cyclopium Westling & 206 & 1 & 1 & - & - & - \\
\hline P. digitatum (Pers. ex Fr.) Saccardo & 207 & 1 & 1 & - & - & - \\
\hline P. expansum Link ex Gray & 210 & 1 & 1 & - & - & - \\
\hline P. frequentans Westling & 211,212 & 2 & 1 & 1 & - & - \\
\hline P. godlewski Zaleski & 214 & 1 & - & 1 & - & - \\
\hline P. nigricans (Bain.) Thom & $222-226$ & 5 & 5 & - & - & - \\
\hline P. somniferum Thom & 234 & 2 & 2 & - & - & - \\
\hline P. viridicatum Westling & 236 & 1 & 1 & - & - & - \\
\hline Total & - & 76 & 71 & 5 & - & - \\
\hline
\end{tabular}

${ }^{*}$ Less than $5 \mathrm{~g} / \mathrm{L}$ medium kojic acid.

** $5-15 \mathrm{~g} / \mathrm{L}$ medium kojic acid.

${ }^{* * *}$ More than $5 \mathrm{~g} / \mathrm{L}$ medium kojic acid.

(Table 1). Also, one isolate of each of Emericella nidulans (number 148) and Eurotium amstelodami (number 155) as species belonging to Aspergillus related genera (based on anamorph/teleomorph) had the ability to produce low levels of kojic acid. Kharchenko [24] studied the ability of 98 strains of $A$. flavus to form kojic acid and recorded 14 strains of them as highly active. This is nearly similar to those recorded in the present investigation (three out of 29 isolates tested of $A$. flavus were recorded as highly producers). Previously, several species of Aspergillus were recorded as kojic acid producers such as A. flavus [25-31], A. oryzae [32, 33], A. fumigatus [28, 34, 35], A. candidus, [33, 36], A. awamori, A. clavatus., A. ustus, and A. wentii [33]. Also, Manabe et al. [33] recorded A. nidulans (=anamorph of Emericella nidulans) as kojic acid producer. Parrish et al. [37], examined the production of kojic acid by 14 species of Aspergillus and recorded the production of the acid by each of $A$. clavatus, A. flavus, A. fumigates, A.oryzae, A. parasiticus, A. tamarii, A. ustus, and A. nidulans
(=Emericella nidulans). Production of kojic acid by A. flavus var. columnaris, A. terreus, A. versicolor, A. phoenicis, A. sclerotiorum, and Eurotium amstelodami recorded in this study for first time, according to the available literatures.

Seventy-six isolates of 24 species of Penicillium belonging to four subgenera were tested for respective abilities to produce kojic acid (Table 2). Only one isolate of each of $P$. spinulosum (number 230), P. janthinellum (number 216), $P$. aurantiogriseum (number 154), P. frequentans (number 211), and $P$. godlewski (number 214) had the ability to produce kojic acid at low concentrations (less than $5 \mathrm{~g} / \mathrm{L}$ medium). Ariff et al. [31] and Burdock et al. [38] reported that kojic acid could be produced by many species of Aspergillus and Penicillium. Parrish et al. [37] tested eight species of Penicillium for kojic acid production and found that each of $P$. puberulum, $P$. estmogenum, $P$. albidum, and $P$. daleae had the ability to produce kojic acid. Production of kojic acid by $P$. citrinum, 
TABLE 3: Production of kojic acid by different isolates belonging to Hyphomycetes and Zygomycetes.

\begin{tabular}{|c|c|c|c|c|c|c|}
\hline \multirow{2}{*}{ Organisms } & \multirow{2}{*}{ Code number } & \multirow{2}{*}{ Total isolates tested } & \multirow{2}{*}{-ve isolates } & \multicolumn{3}{|c|}{ +ve isolates } \\
\hline & & & & Low $^{*}$ & Moderate $^{* *}$ & High $^{* * *}$ \\
\hline \multicolumn{7}{|l|}{ Group: Hyphomycetes } \\
\hline \multicolumn{7}{|l|}{ Family: Dematiaceae } \\
\hline Alternaria alternata (Fries.) Keister & $239-241$ & 3 & 3 & - & - & - \\
\hline Chaetomium globosum Kunze & 242 & 1 & - & 1 & - & - \\
\hline Pleospora herbarum (Fr.) Robenh. Exces. and De Notaris & 247 & 1 & 1 & - & - & - \\
\hline Scopulariopsis brevicaulis (Saccardo) Bainier & 248 & 1 & 1 & - & - & - \\
\hline Stachybotrys chartarum (Ehrenberg) Hughes & 250,251 & 2 & 2 & - & - & - \\
\hline Stachybotrys theobromae Hansf. & 252 & 1 & 1 & - & - & - \\
\hline Torula herbarum (Pres.) Link & 254 & 1 & 1 & - & - & - \\
\hline Trichoderma hamatum (Bon.) Bain. & 255 & 1 & 1 & - & - & - \\
\hline T. koningii Oudemans & 258 & 1 & 1 & - & - & - \\
\hline T. longibrachiatum Rifai & 259 & 1 & 1 & - & - & - \\
\hline T. polysporum (Link ex pres.) Rifai & 262,263 & 2 & 2 & - & - & - \\
\hline \multicolumn{7}{|l|}{ Family: Moniliaceae } \\
\hline Acremonium strictum W. Gams & 237 & 1 & - & - & - & - \\
\hline \multicolumn{7}{|l|}{ Family: Tuberculariaceae } \\
\hline Fusarium aquaeductuum (Radlk. and Rabenh.) & 266 & 1 & 1 & - & - & - \\
\hline F. chlamydosporum Wollenw. and Reinking & $267-269$ & 3 & 3 & - & - & - \\
\hline F. equiseti (Corda) Saccardo & 270,271 & 2 & 1 & 1 & - & - \\
\hline F. lateritium Nees and Sys. & 272 & 1 & 1 & - & - & - \\
\hline F. moniliforme Sheldon & $273-283$ & 11 & 10 & 1 & - & - \\
\hline F. oxysporum Schlecht & $284-295$ & 12 & 11 & - & 1 & - \\
\hline F. proliferatum (Matsushima) Nirenberg & 296 & 1 & 1 & - & - & - \\
\hline F. solani (Mart.) Saccardo & 297 & 1 & 1 & - & - & - \\
\hline F. subglutinans (Wollenw. and Reinking) Nelson & 298 & 1 & 1 & - & - & - \\
\hline F. tricinctum (Corda) Saccardo & 299 & 1 & - & - & - & - \\
\hline \multicolumn{7}{|l|}{ Group: Zygomycetes } \\
\hline \multicolumn{7}{|l|}{ Family: Mucoraceae } \\
\hline Cunninghamella echinulata (Thaxter) Thaxt. ex Blakasles & 315 & 1 & 1 & 1 & - & - \\
\hline C. elegans Landner & 316,317 & 2 & 2 & - & - & - \\
\hline Mucor Circinelliodes van Tieghem & $319-321$ & 3 & 3 & - & - & - \\
\hline M. fuscus Bainier & $329,331,332$ & 3 & 3 & - & - & - \\
\hline \multicolumn{7}{|l|}{ Family: Syncephalastraceae } \\
\hline Syncephalastrum racemosum Cohn and Schroter & 343 & 1 & 1 & - & - & - \\
\hline Total & - & 60 & 55 & 4 & 1 & - \\
\hline
\end{tabular}

${ }^{*}$ Less than $5 \mathrm{~g} / \mathrm{L}$ medium kojic acid.

** $5-15 \mathrm{~g} / \mathrm{L}$ medium kojic acid.

${ }^{* * *}$ More than $5 \mathrm{~g} / \mathrm{L}$ medium kojic acid.

P. griseofulvum, P. rubrum, and P. purpurogenum was previously recorded by Manabe et al. [33].

From 60 isolates belonging to 27 species of 12 genera representing Hyphomycetes (22 species of 9 genera) and Zygomycetes (five species of three genera) were tested for kojic acid production. Only one isolate of each of Fusarium equiseti number 271 (teleomorph: Gibberella intricans), F. moniliforme number 283 (teleomorph: G. fujikuroi), F. oxysporum number 287, F. tricinctum number 299, and Chaetomium globosum number 242 proved to be producers of kojic acid at low or moderate levels (Table 3 ). All these producers belonged to Hyphomycetes while all the tested isolates of Zygomycetes completely failed to produce any detectable amounts of kojic acid. According to the available literatures, there is no record on the production of kojic acid by any members of Hyphomycetes or Zygomycetes. The higher producer isolates of kojic acid (A. flavus numbers 7, 23, and 24 and A. flavus var. columnaris numbers 36 and 41) were selected for comparison between static and shaking cultivation methods. Generally, the concentrations of kojic acid produced were increased when submerged cultivation (shaking) was used than those recorded using 
TABLE 4: Comparison between surface (static) and submerged (shaking) cultivation for kojic acid production $(\mathrm{g} / \mathrm{L})$ using the synthetic medium by the five highly producer organisms.

\begin{tabular}{lccc}
\hline Organisms & $\begin{array}{c}\text { Code } \\
\text { number }\end{array}$ & $\begin{array}{c}\text { Static } \\
\text { cultivation }\end{array}$ & $\begin{array}{c}\text { Shaking } \\
\text { cultivation }\end{array}$ \\
\hline Aspergillus flavus & 24 & 16.3 & 18.3 \\
A. flavus & 23 & 18.5 & 28.5 \\
A. flavus & 7 & 21.4 & 34.4 \\
A. flavus var. columnaris & 36 & 21.4 & 22.8 \\
A. flavus var. columnaris & 41 & 15.3 & 26.3 \\
\hline
\end{tabular}

surface cultivation (static) (Table 4). Kojic acid levels produced by the five isolates grown using shaking cultivation were fluctuated between 18.3 and $34.4 \mathrm{~g} / \mathrm{L}$ medium, while those levels recorded using static cultivation ranged from 16.3 to $21.4 \mathrm{~g} / \mathrm{L}$ medium. The high concentration of kojic acid $(34.4 \mathrm{~g} / \mathrm{L})$ was formed by $A$. flavus number 7 using shaking cultivation. Nearly similar results were recorded by Ariff et al. [31]. They found that the level of kojic acid accumulated by $A$. flavus strain $44-1$ using rotary shaker was $32.5 \mathrm{~g} / \mathrm{L}$. Rosfarizan and Ariff [39] found that the highest level of kojic acid production by $A$. flavus strain $44-1$ reached $39.9 \mathrm{~g} / \mathrm{L}$ in submerged batch fermentation.

Manabe et al. [32] produced kojic acid at $40 \mathrm{mg} / \mathrm{mL}$ medium $(=40 \mathrm{~g} / \mathrm{L})$ A. flavus isolated from Japanese fermented foods. El-Kady et al. [35] recorded 57-59 mg of kojic acid per $\mathrm{mL}$ medium formed by $A$. fumigatus isolated from Buffalo pneumonia. High concentration of kojic acid $(60 \mathrm{~g} / \mathrm{L}$ medium) was recorded by El-Sharkawy [30] using calcium alginate immobilization technique for kojic acid production by A. flavus ATCC 9179. Kwak and Rhee [40] produced kojic acid using, also, immobilized cells of $A$. oryzae and recorded a very high kojic acid production level (reached up to $80 \mathrm{~g} / \mathrm{L}$ ) in repeated batch culture. Higher final concentrations of kojic acid in solution caused kojic acid to crystallize in the form of fine needles $[9,40]$ and this is very useful for easy and low cost recovery. On the other hand, low level of kojic acid was recorded by Ogawa et al. [41], who reported that the maximum yield of kojic acid was around $20 \mathrm{mg} / \mathrm{mL}$ formed by $A$. oryzae NRRL 484 using shaking culture. Wakisaka et al. [42] found that the kojic acid level produced by A. oryzae NRRL 484 the same isolate used by Ogawa et al. [41] using shaking flask cultures was $24 \mathrm{~g} / \mathrm{L}$. The superior isolate $(A$. flavus Number 7) for kojic acid production (which formed $34.4 \mathrm{~g} / \mathrm{L}$ of kojic acid using shaking cultivation) was selected, using this cultivation method for a series of experiments to determine the effect of some nutritional and environmental conditions on the efficiency of kojic acid production by this isolate. This is for maximization of kojic acid production. This study explained that optimal nutritional conditions for this isolate were $100 \mathrm{~g} / \mathrm{L}$ glucose, $5.0 \mathrm{~g} / \mathrm{L}$ yeast extract, and $1.5 \mathrm{~g} / \mathrm{L} \mathrm{KH}_{2} \mathrm{PO}_{4}$ as carbon, nitrogen, and phosphorus sources, respectively. The optimal $\mathrm{pH}$, temperature, and incubation period as environmental conditions were $\mathrm{pH} 3,30^{\circ} \mathrm{C}$, and 10 days, respectively. These results are completely similar to those recorded by several investigators [31, 39, 43, 44].
An attempt has been made, in this study, to investigate the possibility to utilization of agro-industrial wastes or byproducts as natural medium for kojic acid production by the five high producer isolates (A. flavus numbers 7, 23, and 24 and A. flavus var. columnaris numbers 36 and 41 ). The agroindustrial wastes and by-products used in this study were pea, kidney bean, and mixed vegetables wastes; the wastes of juice production of each of apple, apricot, orange, and peach; the wastes of other vegetables used as pickles, namely, carrot and turnip; three industrial by-products, namely, corn steep liquor, molasses, and cheese whey; in addition to three agricultural by-products as wheat bran, rice husk, and rice fragments (Tables 5, 6, and 7). Generally, kojic acid production levels by the five tested fungal isolates grown on any wastes or by-products under investigation were relatively low (ranged from 0.0 to $21.2 \mathrm{~g} / \mathrm{L}$ medium) comparing to those levels produced by the same fungal isolates on synthetic medium which ranged from 18.3 to $34.4 \mathrm{~g} / \mathrm{L}$ medium. Low levels of kojic acid production by the high producer isolates grew on a medium containing carbon sources other than glucose were previously recorded $[39,44,45]$. Rosfarizan and Ariff [39] reported that the level of kojic acid production by $A$. flavus strain $44-1$ was $4.4 \mathrm{~g} / \mathrm{L}$ in submerged batch fermentation using lactose as carbon source. Also, they reported that glucose was the best out of seven carbon sources tested (glucose, xylose, sucrose, fructose, lactose, maltose, and starch) for kojic acid production. Rosfarizan et al. [44] found that the maximum yield of kojic acid by $A$. flavus strain 44-1 grown on gelatinized sago starch as carbon source was $4.51 \mathrm{~g} / \mathrm{L}$. Moreover, no kojic acid was produced by A. oryzae when starch was used as carbon source as recorded by Kitada et al. [43]. Rice fragments and molasses as byproducts were relatively suitable substrates, for kojic acid production by the five fungal isolates tested. The two tested isolates of A. flavus var. columnaris (numbers 36 and 41) in addition to one isolate of $A$. flavus (number 7) could use rice fragments as by-product medium and produce relatively high levels of kojic acid (21.2, 18.2 and 12.1 g/L, resp.), while the other two isolates tested of A. flavus (numbers 23 and 24) formed relatively high levels of the acid (9.3 and $5.1 \mathrm{~g} / \mathrm{L}$, resp.) on molasses medium (Table 7).

Egyptian sugar cane molasses contain about $44 \%$ as total sugar (glucose, sucrose, and fructose), $0.46 \%$ as total nitrogen in addition to detectable amounts of some vitamins such as riboflavin and thiamin [46, 47]. Lai et al. [48] reported that the main chemical characteristics of rice husk contain: carbon (45.3\%), hydrogen (5.5\%), nitrogen (0.67\%), sulfur $(0.29 \%)$, and chlorine $(0.29)$ in addition to detectable amounts of potassium (1630 ppm), calcium $(94 \mathrm{ppm})$, iron (202 ppm), sodium (207 ppm), zinc (24 ppm), magnesium (699), phosphorus (94 ppm), and other. Presence of these compounds in each of molasses and rice husk may favor kojic acid production. El-Refai and El-kady [49] and Ghanem et al. [50] reported the possible utilization of molasses for sterols production by yeast and filamentous fungi, respectively. Kahraman and Yesilada [51] used industrial and agricultural wastes as substrates for laccase production by Coriolus versicolor ATCC 200801 and Funalia trogii ATCC 200800 as white rot fungi and recommended using these 
TABLE 5: Production of kojic acid (g/L) by the selected five highly producer organisms grown on vegetables and pickles wastes as well as synthetic media for 10 days as shaking cultivation.

\begin{tabular}{|c|c|c|c|c|c|c|c|}
\hline \multirow{2}{*}{ Fungal isolates tested } & \multirow{2}{*}{$\begin{array}{l}\text { Code } \\
\text { number }\end{array}$} & \multirow{2}{*}{ Synthetic medium } & \multicolumn{3}{|c|}{ Kind of vegetable wastes } & \multicolumn{2}{|c|}{ Kind of pickles wastes } \\
\hline & & & Pea & Kidney bean & Mixed vegetable & Carrot & Turnip \\
\hline Control $^{*}$ & - & - & - & - & - & - & - \\
\hline Aspergillus flavus & 24 & 18.3 & 5.5 & 0.4 & 0.8 & 0.0 & 1.5 \\
\hline A. flavus & 23 & 28.5 & 2.1 & 0.1 & 0.3 & 0.6 & 0.5 \\
\hline A. flavus & 7 & 34.4 & 2.5 & 0.8 & 0.2 & 0.0 & 0.6 \\
\hline A. flavus var. columnaris & 36 & 22.8 & 1.1 & 2.0 & 0.2 & 0.0 & 0.9 \\
\hline A. flavus var. columnaris & 41 & 26.3 & 0.9 & 0.1 & 1.0 & 0.0 & 1.6 \\
\hline
\end{tabular}

${ }^{*}$ Control: wastes or by-products without fungal inoculum.

TABLE 6: Production of kojic acid (g/L) by the selected five highly producer organisms grown on fruit wastes as well as synthetic media for 10 days as shaking cultivation.

\begin{tabular}{lccccc}
\hline Fungal isolates tested & \multirow{2}{*}{ Code number } & Synthetic medium & Apple & \multicolumn{2}{c}{ Kind of fruit wastes } \\
Apricot & Orange & - & - \\
Peach
\end{tabular}

${ }^{*}$ Control: wastes or by-products without fungal inoculum.

TABLE 7: Production of kojic acid (g/L) by the selected five highly producer organisms grown on agriculture and industrial by-products as well as synthetic media for 10 days as shaking cultivation.

\begin{tabular}{|c|c|c|c|c|c|c|c|c|}
\hline \multirow{2}{*}{ Fungal isolates tested } & \multirow{2}{*}{ Code number } & \multirow{2}{*}{ Synthetic medium } & \multicolumn{3}{|c|}{ Kind of agriculture by-products } & \multicolumn{3}{|c|}{ Kind of industrial by-products } \\
\hline & & & Wheat bran & Rice fragment & Rice husk & Corn steep liquor & Molasses & Whey \\
\hline Control $^{*}$ & - & - & - & - & - & - & - & - \\
\hline Aspergillus flavus & 24 & 18.3 & 3.0 & 5.3 & 2.8 & 0.0 & 9.3 & 0.0 \\
\hline A. flavus & 23 & 28.5 & 1.0 & 0.9 & 0.1 & 1.3 & 5.1 & 0.1 \\
\hline A. flavus & 7 & 34.4 & 0.7 & 12.1 & 0.1 & 0.0 & 6.2 & 0.0 \\
\hline A. flavus var. columnaris & 36 & 22.8 & 2.0 & 21.2 & 0.1 & 3.1 & 4.0 & 0.0 \\
\hline A. flavus var. columnaris & 41 & 26.3 & 1.6 & 18.2 & 1.6 & 0.4 & 3.7 & 0.0 \\
\hline
\end{tabular}

${ }^{*}$ Control: wastes or by-products without fungal inoculum.

TABle 8: Production of kojic acid (g/L) by the selected five highly producer isolate (A. flavus number 7) grown on the synthetic medium for 14 days using a laboratory fermentor.

\begin{tabular}{lc}
\hline Fermentation period (days) & Kojic acid $(\mathrm{g} / \mathrm{L})$ \\
\hline 2 & 28.6 \\
4 & 31.5 \\
6 & 48.3 \\
8 & 53.5 \\
10 & 51.6 \\
12 & 50.8 \\
14 & 47.1 \\
\hline
\end{tabular}

waste in the production of important lignocellulolytic and other biotechnological enzymes, respectively. Sallam et al. [52] used a medium composed of cane sugar molasses (3\%) and corn steep liquor (1\%) for cyclosporin A (which used as a powerful immunosuppressant to prevent graft rejection in transplantation surgery) production by $A$. terreus and recorded the production of $45.23 \mathrm{mg}$ cyclosporin A per each one liter medium. More recently, Ragaa Kotby [20] found that ten fungal isolates (one of each of A. ustus, Fusarium nivale, F. oxysporum, F. moniliforme, Trichoderma hamatum, and T. pseudokoningii in addition to four isolates of T. harzianum) had the ability to grow well and produce cyclosporin A at levels fluctuated between 400 and $1200 \mu \mathrm{g} / 50 \mathrm{~mL}$ of $10 \%$ molasses medium.

Production of kojic acid by the superior producer isolate (A. flavus number 7), recorded in this study, grew on the synthetic medium using a 1.5 laboratory fermentor (semiindustrial scale) was the target in the last experiment of this part in this investigation (Table 8 ). The results revealed that at the first two days, kojic acid concentration reached 
$28.6 \mathrm{~g} / \mathrm{L}$. After this time, kojic acid levels were increased gradually with the increase of fermentation time and reaching maximum level $(53.5 \mathrm{~g} / \mathrm{L})$ after eight days of inoculation. Gradual decrease in kojic acid concentrations was recorded with further extension of fermentation period. These results are in harmony with that previously obtained by Ariff et al. [31]. They used a fermentor $(2 \mathrm{~L} \mathrm{~B}$, Braum stirred tank fermentor, Biostat. B) For kojic acid production by $A$. flavus strain 44-1 and found that kojic acid concentration reached up to $36.5 \mathrm{~g} / \mathrm{L}$ after 11 days. Also, reduction of kojic acid formation after the concentration became maximum was observed by Ariff et al. [31] and El-Assar [53]. They attribute this reduction to degradation of kojic acid to oxalic and acetic acid by the mycelium under glucose depleted conditions [23, 31, 54, 55]. Futamura et al. [56] produced kojic acid by $A$. oryzae MK-107-39 in a jar fermentor and recorded that level of kojic acid reached up to $40 \mathrm{~g} / \mathrm{L}$. On the other hand, Wakisaka et al. [42] produced kojic acid by $A$. oryzae NRRL 484 using continuous membrane surface liquid culture technique and recorded that kojic acid concentration reached $45 \mathrm{mg} / \mathrm{mL}$ medium and nearly constant after 15 days of cultivation for over 70 days.

In view of the wide use of kojic acid as a food ingredient (flavor enhancers, antioxidant, and/or discoloration) [57, 58], skin-lightening agent in cosmetic or dermatological preparations [22,59], bacterial inhibitor, pain Killer, and antiinflammatory agent in medical field [60], preventer for the undesirable melanosis (blackening) of agricultural products $[45,61]$ and many other uses, it seemed necessary to conduct a thorough investigation of production of kojic acid on large scale.

\section{Conflict of Interests}

The authors declare that they have no conflict of interests regarding the publication of this paper.

\section{References}

[1] Y. Niwa and H. Akamatsu, "Kojic acid scavenges free radicals while potentiating leukocyte functions including free radical generation," Inflammation, vol. 15, no. 4, pp. 303-315, 1991.

[2] List of Food Additives Other Than Chemical Synthetics, notification no. 207, Ministry of Health and Welfare, Tokyo, Japan, 1989.

[3] F. C. Wehner, P. G. Thiel, S. J. van Rensburg, and I. P. C. Demasius, “Tested on chicken embryos," Toxicology Letters, vol. 13, pp. 239-245, 1978.

[4] A. J. St. Angelo, J. R. Vercellotti, H. P. Dupuy, and A. M. Spanier, "Assessment of beef flavor quality, a multidisciplinary approach," Food Technology, vol. 42, pp. 133-138, 1988.

[5] R. F. Theiler, K. Sato, T. G. Aspelund, and A. F. Miller, "Inhibition of $N$-nitrosamine formation in a cured ground pork belly model system," Journal of Food Science, vol. 49, no. 2, pp. 341-344, 1984.

[6] P. J. Curtis, "Chemical introduction of local reddening in strawberry fruits," Journal of the Science of Food and Agriculture, vol. 28, pp. 243-246, 1977.

[7] H. Tanigaki, H. Obata, and T. Tokuyama, "The determination of kojic acid using the stopped-flow method," Bulletin of the Chemical Society of Japan, vol. 35, pp. 3195-3197, 1980.
[8] M. Uher, J. Brtko, O. Rajniakova, M. Kovac, and E. Novotana, "Kojic acid and its derivatives in cosmetics and health protection," Parfuem-Kosmetik, vol. 74, pp. 554-556, 1993.

[9] M. Rosfarizan, S. M. Mohd, S. Nurashikin, M. S. Madihah, and B. A. Arbakariya, "Kojic acid: applications and development of fermentation process for production," Biotechnology and Molecular Biology Reviews, vol. 5, no. 2, pp. 24-37, 2010.

[10] R. L. Beard and G. S. Walton, "Kojic acid as an insecticidal mycotoxin," Journal of Invertebrate Pathology, vol. 14, no. 1, pp. 53-59, 1969.

[11] S. Y. Shetty and R. M. Sathe, "Sequential determination of thorium and rare earths with EDTA and kojic acid," Talanta, vol. 23, no. 1, pp. 46-47, 1976.

[12] F. C. Wehner, P. G. Thiel, S. J. van Rensburg, and I. P. C. Demasius, "Mutagenicity to Salmonella typhimurium of some Aspergillus and Penicillium mycotoxins," Mutation Research, vol. 58, no. 2-3, pp. 193-203, 1978.

[13] I. A. El-kady, M. H. Moubasher, and M. Eman Mostafa, "Glycerol production by two filamentous fungi grown at different ionic and monionic osmotics and cheese whey," Folia Microbiologica, vol. 39, no. 3, pp. 203-207, 1994.

[14] A. A. Zohri, "Glycerol production from cheese whey by selected fungal cultures," Journal of Food Science and Technology, vol. 37, no. 5, pp. 533-538, 2000.

[15] N. R. Khamaruddin, M. Basri, G. E. C. Lian et al., "Enzymatic synthesis and characterization of palm-based kojic acid ester," Journal of Oil Palm Research, vol. 20, pp. 461-469, 2008.

[16] I. A. El-kady, A. A. Zohri, E. M. Mostafa, and S. M. Ragaa, "Lipid and sterol production by moulds on sugar can molasses by products," in Proceeding of the 1st International Conference on Fungi: Hopes and Challenges, vol. 1, pp. 87-98, Al-Azhar University, Cairo, Egypt, September 1996.

[17] E. M. Mostafa and A. A. Zohri, "Utilization of sugar cane molasses for lipid, sterol and ergosterol production by Cochliobolus spicifer Nelson," African Journal of Mycology and Biotechnology, vol. 5, no. 2, pp. 63-72, 1997.

[18] S. S. El-Maraghy, A. A. Zohri, and E. M. S. A. Mostafa, "Accumulation of lipid and sterol by some isolates of Aspergillus niger and A. flavus groups utilizing whey under the influence of trace elements," in Proceedings of the 3rd Saudi Symposium on Food and Nutrition, pp. 107-116, Faculty of Agriculture, King Saud University, October 1998.

[19] M. S. M. Abd-El-Galil, Side chain degradation and some biological transformations of progesterone by fungi [Ph.D. thesis], Department of Botany, Faculty of Science, Assiut University, Assiut, Egypt, 2000.

[20] S. M. Ragaa Kotby, Production of cyclosporins (immunosuppressive drugs) by fungi [Ph.D. thesis], Department of Botany, Faculty of Science, Assiut University, Assiut, Egypt, 2006.

[21] J.-M. Noh, S.-Y. Kwak, H.-S. Seo, J.-H. Seo, B.-G. Kim, and Y.-S. Lee, "Kojic acid-amino acid conjugates as tyrosinase inhibitors," Bioorganic and Medicinal Chemistry Letters, vol. 19, no. 19, pp. 5586-5589, 2009.

[22] A. P. D. Rodrigues, A. S. C. Carvalho, A. S. Santos, C. N. Alves, J. L. M. do Nascimento, and E. O. Silva, "Kojic acid, a secondary metabolite from Aspergillus sp., acts as an inducer of macrophage activation," Cell Biology International, vol. 35, no. 4, pp. 335-343, 2011.

[23] M. S. Madiha, A. G. Baharuddin, M. I. A. Karim et al., "Cultivation characteristics during kojic acid fermentation by local fungus, mutant strain 44-1," in Proceedings of the 2nd 
UNESCO National Workshop on Promotion of Microbiology in Malaysia, Universiti Pertanian Malaysia, Selangor, Malaysia, 1993.

[24] S. M. Kharchenko, "The biosynthesis of kojic acid by Aspergillus flavus link strains isolated from feed," Mikrobiolohichnyi Zhurnal, vol. 61, no. 4, pp. 15-21, 1999.

[25] M. El Khadem, M. S. Tewfik, and Y. A. Hamdi, "The stimulatory effect of kojic acid on the production of aflatoxin by isolates of Aspergillus flavus link," Zentralblatt für Bakteriologie, Parasitenkunde, Infektionskrankheiten und Hygiene, vol. 131, no. 6, pp. 497-500, 1976.

[26] P. M. Scott, "Mycotoxins in feeds and ingredients and their origin," Journal of Food Protection, vol. 41, pp. 385-398, 1978.

[27] S. N. Kharchenko, A. I. Yatsyshin, and L. Y. Magdenko, "Koetoxicosis (kojic acid poisoning) in poultry," Veterinariya, vol. 9, pp. 70-73, 1986.

[28] S. N. Kharchenko, A. I. Iatsyshin, E. M. Tea, N. K. Pototskiǐ, and O. I. Pavlenko, "The species composition of the micromycetes in feed and their role in animal kojic acid toxicosis," Mikrobiologicheskii Zhurnal, vol. 55, no. 3, pp. 78-84, 1993.

[29] S. E. Megalla, A. Y. Nassar, and M. A. Gohar, "The role of copper(I)-nicotinic acid complex on kojic acid biosynthesis by Aspergillus flavus," Journal of Basic Microbiology, vol. 27, no. 1, pp. 29-33, 1987.

[30] S. H. El-Sharkawy, "Kojic acid production from cocoa juice by Aspergillus flavus entrapped in calcium alginate," Bollettino Chimico Farmaceutico, vol. 134, no. 6, pp. 316-319, 1995.

[31] A. B. Ariff, M. Rosfarizan, L. S. Herng, S. Madihah, and M. I. A. Karim, "Kinetics and modelling of kojic acid production by Aspergillus flavus link in batch fermentation and resuspended mycelial system," World Journal of Microbiology and Biotechnology, vol. 13, no. 2, pp. 195-201, 1997.

[32] M. Manabe, T. Goto, K. Tanaka, and S. Matsuura, "The capabilities of Aspergillus flavus group to produce aflatoxins and kojic acid," Report of National Food Research Institute, vol. 38, pp. 115120, 1981.

[33] M. Manabe, K. Tanaka, T. Goto, and S. Matsura, "Producing capability of kojic acid and aflatoxin by mould," Developments in Food Science, vol. 7, pp. 4-14, 1984.

[34] A. H. Moubasher, M. I. A. Abdel-Kader, and I. A. El-Kady, "Toxigenic fungi isolated from Roquefort cheese," Mycopathologia, vol. 66, no. 3, pp. 187-190, 1979.

[35] I. A. El-kady, M. B. Mazen, I. S. A. Abd Allah, and A. H. Elyas, "Toxigenicity and toxins produced by fungi isolated from clinically positive pneumonic cases of buffalo Calves," Assiut Veterinary Medical Journal, vol. 12, pp. 85-88, 1984.

[36] C. I. Wei, I. S. Huang, J. S. Chen, M. R. Marshall, and K. I. Chung, "Production of kojic acid by Aspergillus candidus in three culture media," Journal of Food Protection, vol. 54, pp. 546548, 1991.

[37] F. W. Parrish, B. J. Wiley, E. G. Simmons, and L. Long Jr., "Production of aflatoxins and kojic acid by species of Aspergillus and Penicillium," Applied Microbiology, vol. 14, no. 1, p. 139, 1966.

[38] G. A. Burdock, M. G. Soni, and I. G. Carabin, "Evaluation of health aspects of kojic acid in food," Regulatory Toxicology and Pharmacology, vol. 33, no. 1, pp. 80-101, 2001.

[39] M. Rosfarizan and A. B. Ariff, "Kinetics of kojic acid fermentation by Aspergillus flavus using different types and concentrations of carbon and nitrogen sources," Journal of Industrial Microbiology and Biotechnology, vol. 25, no. 1, pp. 20-24, 2000.
[40] M. Y. Kwak and J. S. Rhee, "Cultivation characteristics of immobilized Aspergillus oryzae for kojic acid production," Biotechnology and Bioengineering, vol. 39, no. 9, pp. 903-906, 1992.

[41] A. Ogawa, Y. Wakisaka, T. Tanaka, T. Sakiyama, and K. Nakanishi, "Production of kojic acid by membrane-surface liquid culture of Aspergillus oryzae NRRL484," Journal of Fermentation and Bioengineering, vol. 80, no. 1, pp. 41-45, 1995.

[42] Y. Wakisaka, T. Segawa, K. Imamura, T. Sakiyama, and K. Nakanishi, "Development of a cylindrical apparatus for membrane-surface liquid culture and production of kojic acid using Aspergillus oryzae NRRL484," Journal of Fermentation and Bioengineering, vol. 85, no. 5, pp. 488-494, 1998.

[43] M. Kitada, H. Ueyama, E. Suzuki, and T. Fukumbara, "Studies on kojic acid fermentation. 1: culture conditions in submerged culture," Journal of Fermentation Technology, vol. 45, pp. 11011107, 1967.

[44] M. Rosfarizan, A. Arbakariya, M. Ali Hassan, M. I. Abdul Karim, S. Hiroshi, and S. Suteaki, "Importance of carbon source feeding and $\mathrm{pH}$ control strategies for maximum kojic acid production from sago starch by Aspergillus flavus," Journal of Bioscience and Bioengineering, vol. 94, no. 2, pp. 99-105, 2002.

[45] S. E. Ashari, R. Mohamad, A. Ariff, M. Basri, and A. B. Salleh, "Optimization of enzymatic synthesis of palm-based kojic acid ester using response surface methodology," Journal of Oleo Science, vol. 58, no. 10, pp. 503-510, 2009.

[46] A. H. El-Refai, Physiological and biochemical studies on the metabolism of fats and sterols in fungi [Ph.D. thesis], Cairo University, Giza, Egypt, 1964.

[47] M. S. Khalifa, Studies on production of single cell protein from vinasse [M.S. thesis], Sugar Technology Research Institute, Assiut University, Assiut, Egypt, 2003.

[48] L.-S. T. Lai, T.-H. Tsai, T. C. Wang, and T.-Y. Cheng, "The influence of culturing environments on lovastatin production by Aspergillus terreus in submerged cultures," Enzyme and Microbial Technology, vol. 36, no. 5-6, pp. 737-748, 2005.

[49] A. H. El-Refai and I. A. El-kady, "Utilization of some industrial by-products for the micro-biological production of sterol from Sccharomyces fermentati," Journal of Botany of the United Arab Republic, vol. 12, no. 1, pp. 45-54, 1969.

[50] K. M. Ghanem, N. B. Ghanem, and A. H. El-Refai, "Utilization of beet molasses for sterol production by some moulds," Microbiologia, vol. 6, no. 1, pp. 37-44, 1990.

[51] S. Kahraman and O. Yeilada, "Industrial and agricultural wastes as substrates for laccase production by white-rot fungi," Folia Microbiologica, vol. 46, no. 2, pp. 133-136, 2001.

[52] L. A. R. Sallam, A.-M. H. El-Refai, A.-H. A. Hamdy, H. A. El-Minofi, and I. S. Abdel-Salam, "Role of some fermentation parameters on cyclosporin A production by a new isolate of Aspergillus terreus," Journal of General and Applied Microbiology, vol. 49, no. 6, pp. 321-328, 2003.

[53] S. A. El-Aasar, "Cultural conditions studies on kojic acid production by Aspergillus parasiticus," International Journal of Agriculture and Biology, vol. 8, pp. 468-473, 2006.

[54] P. Bajpai, P. K. Agrawal, and L. Vishwanathan, "Kojic acid synthesis and propertie," Journal of Scientific \& Industrial Research, vol. 41, pp. 185-194, 1982.

[55] R. Mohamad and A. B. Ariff, "Biotransformation of various carbon sources to kojic acid by cell-bound enzyme system of A. flavus link 44-1," Biochemical Engineering Journal, vol. 35, no. 2, pp. 203-209, 2007. 
[56] T. Futamura, H. Ishihara, T. Tamura et al., "Kojic acid production in an airlift bioreactor using partially hydrolyzed raw corn starch," Journal of Bioscience and Bioengineering, vol. 92, no. 4, pp. 360-365, 2001.

[57] M. S. LeBlanc and H. A. Akers, "Maltol and ethyl maltol, from larch tree to successful food additives," Food Technology, vol. 26, pp. 78-87, 1989.

[58] G. J. Nohynek, D. Kirkland, D. Marzin, H. Toutain, C. LeclercRibaud, and H. Jinnai, "An assessment of the genotoxicity and human health risk of topical use of kojic acid [5-hydroxy-2(hydroxymethyl)-4H-pyran-4-one]," Food and Chemical Toxicology, vol. 42, no. 1, pp. 93-105, 2004.

[59] H. Nakayama, T. Ebihara, N. Satoh, and T. Jinnai, "Depigmentation agents," in Cosmeceuticals: Drugs vs. Cosmetics, P. Elsner and H. Maibach, Eds., pp. 123-144, Marcel Dekker, New York, NY, USA, 2001.

[60] Anon, Sansei Pharmaceutical Company, Japan. Personal Communications, 1992.

[61] J. S. Chen, C. Wei, and M. R. Marshall, "Inhibition mechanism of kojic acid on polyphenol oxidase 1," Journal of Agricultural and Food Chemistry, vol. 39, no. 11, pp. 1897-1901, 1991. 

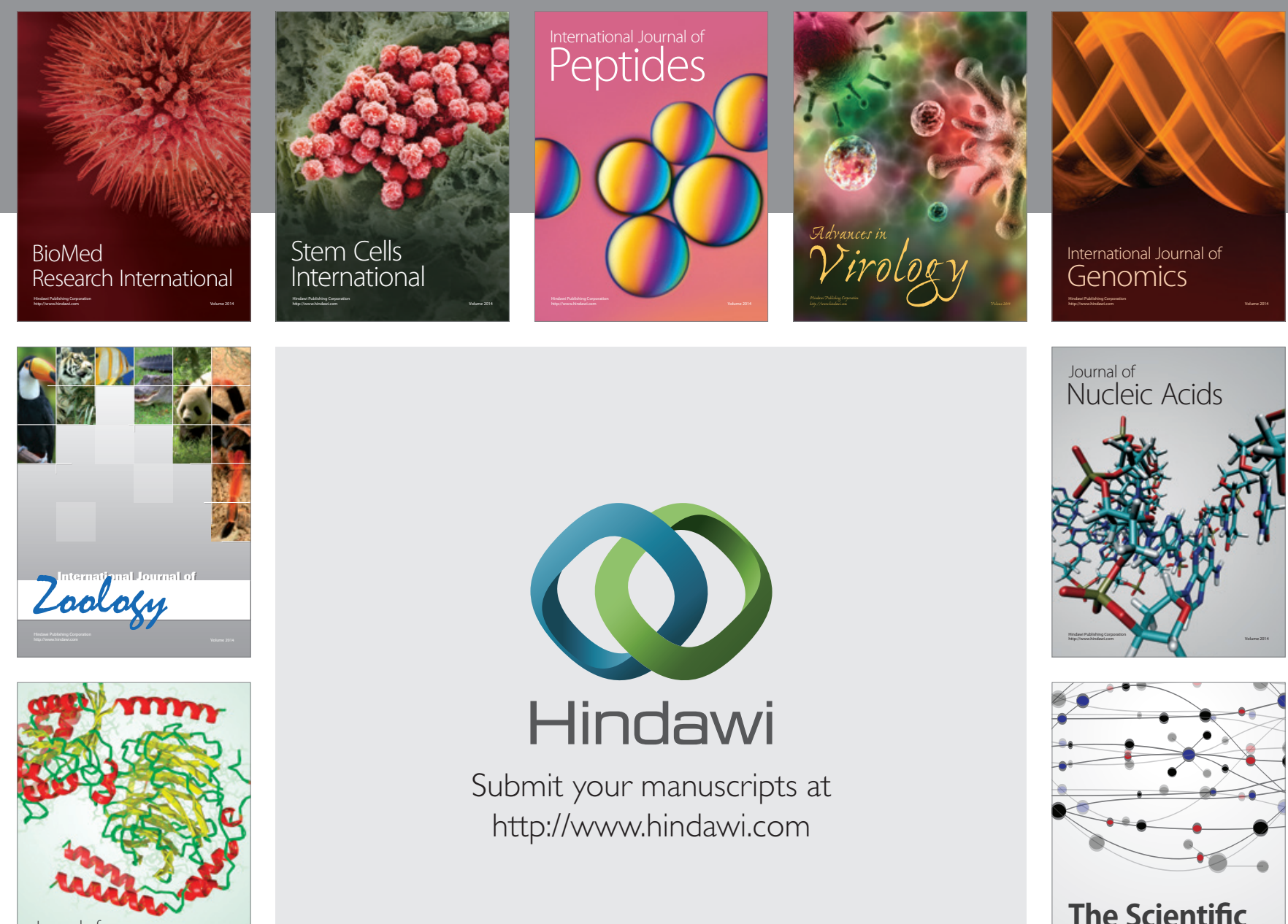

Submit your manuscripts at

http://www.hindawi.com

Journal of
Signal Transduction
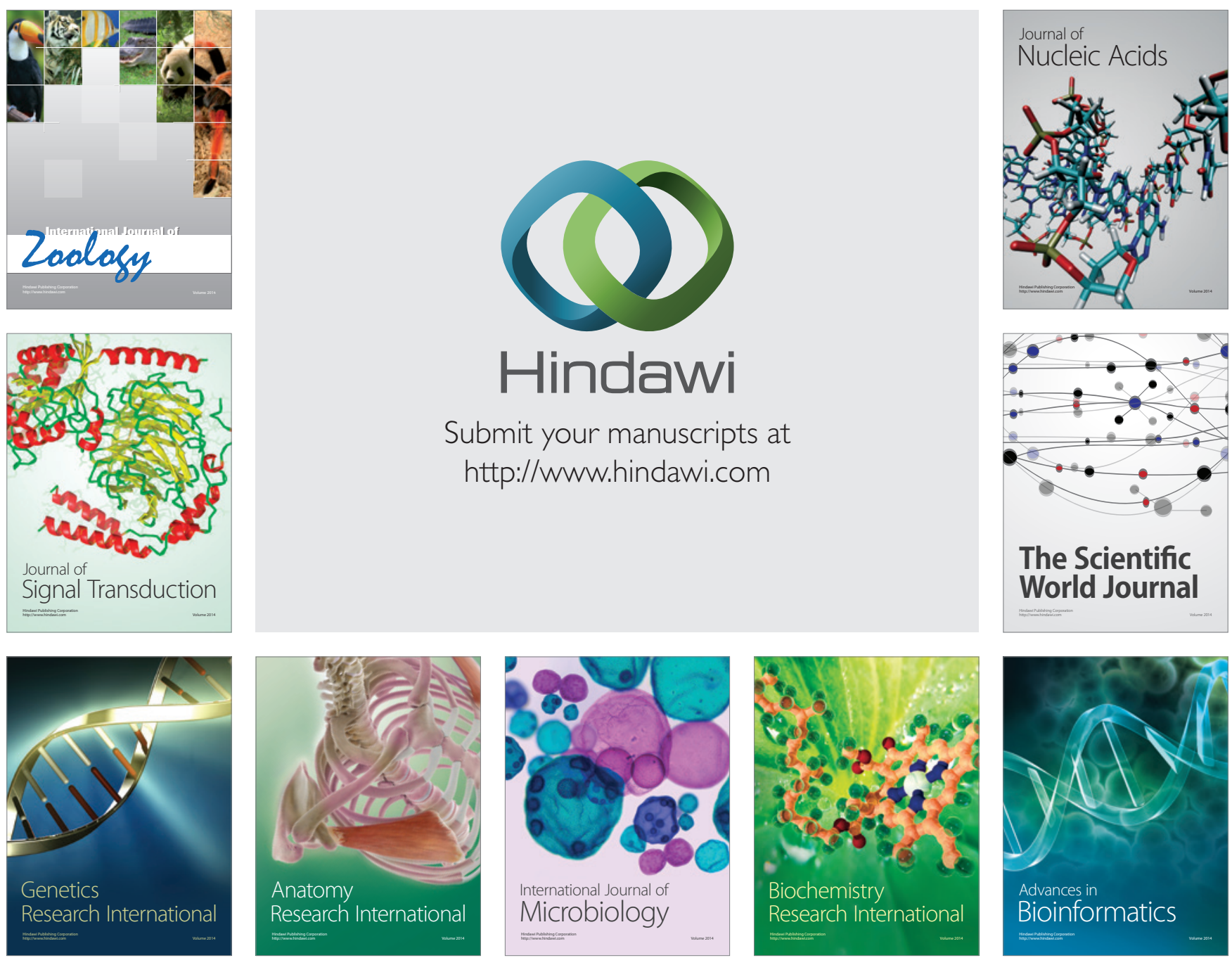

The Scientific World Journal
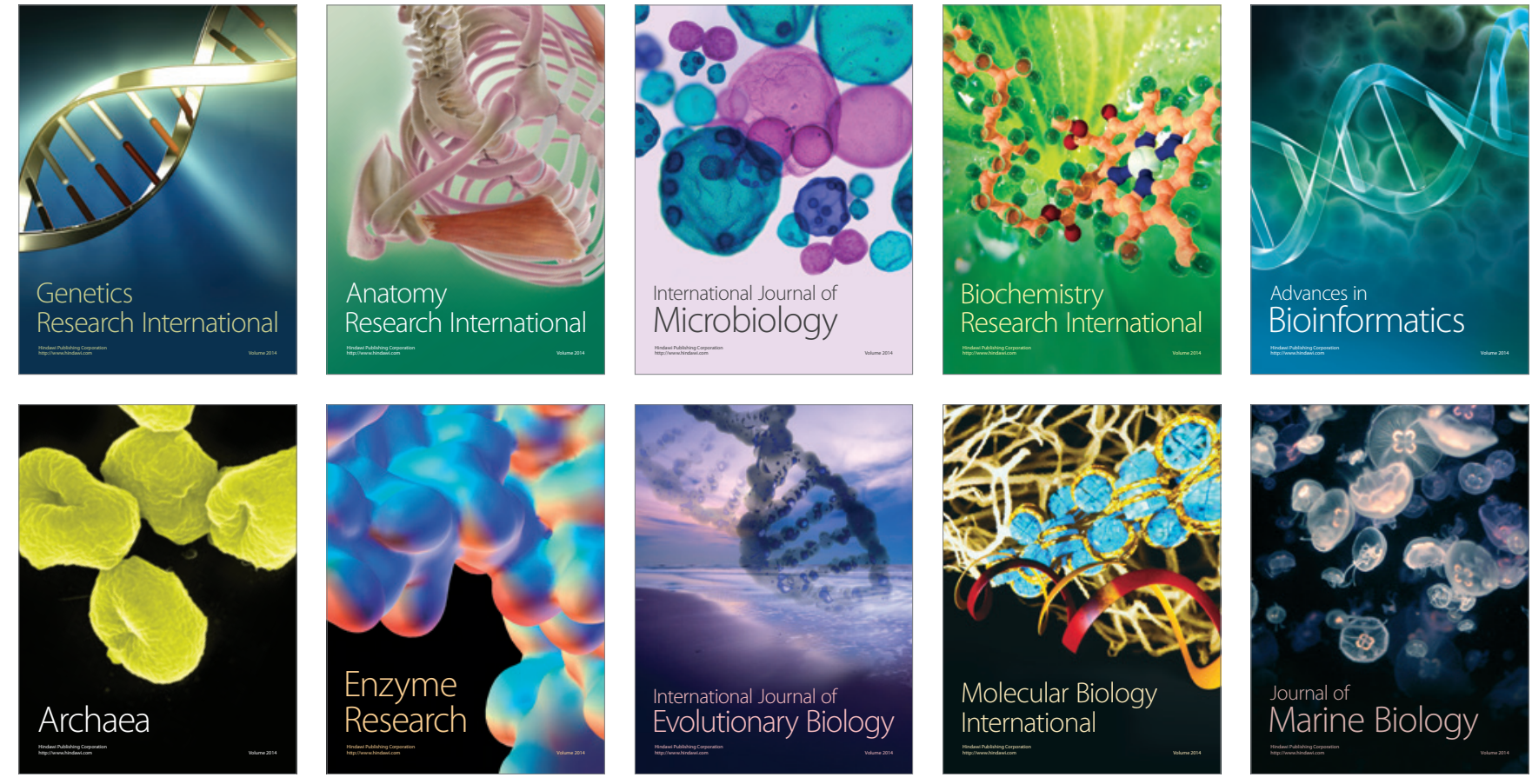